OPEN ACCESS

Edited by:

Erwin Dreesen,

KU Leuven, Belgium

Reviewed by:

Ivan Romic,

University Hospital Centre Zagreb,

Croatia

Caren Lee Hughes,

Mayo Clinic Florida, United States

${ }^{*}$ Correspondence:

Tiecheng Yu

yutc@jlu.edu.cn

Specialty section:

This article was submitted to Obstetric and Pediatric Pharmacology,

a section of the journal

Frontiers in Pharmacology

Received: 21 May 2021

Accepted: 30 June 2021

Published: 06 August 2021

Citation:

Li J, Xie X, Liu W, Gu F, Zhang K, Su Z, Wen Q, Sui Z, Zhou P and Yu T (2021)

Acid-Suppressive Drugs and Risk of

Fracture in Children and Young Adults:

A Meta-Analysis of

Observational Studies.

Front. Pharmacol. 12:712939.

doi: 10.3389/fphar.2021.712939

\section{Acid-Suppressive Drugs and Risk of Fracture in Children and Young Adults: A Meta-Analysis of Observational Studies}

\author{
Jiangbi Li ${ }^{1}$, Xiaoping Xie ${ }^{1}$, Weibing $L_{i u^{2}}{ }^{2}$ Feng Gu ${ }^{1}$, Ke Zhang ${ }^{1}$, Zilong Su ${ }^{1}$, Qiangqiang Wen ${ }^{1}$, \\ Zhenjiang Sui ${ }^{1}$, Pengcheng Zhou ${ }^{1}$ and Tiecheng $\mathrm{Yu}^{1 *}$ \\ ${ }^{1}$ Department of Orthopedics, The First Hospital of Jilin University, Changchun, China, ${ }^{2}$ Department of Orthopedics, The First \\ People's Hospital of Yunnan Province, Kunming, China
}

Background: Recent studies have suggested that proton pump inhibitors (PPIs) and histamine type 2 receptor antagonists (H2RAs) may increase the risk of fracture. We performed a meta-analysis to evaluate the risk of fracture with PPIs and H2RAs use in children and young adults.

Methods: PubMed, EMBASE database, Cochrane Library, and Web of Science for relevant articles published before May 2021 were searched. We included all the observational studies reporting on the risk of fracture with acid-suppressive drug (PPIs and H2RAs) use in children and young adults. We calculated pooled risk ratios (RRs) for fracture using random-effects models and conducted subgroup analyses.

Results: A total of six studies were included in our analysis. Pooled analysis of PPIs use showed significant risk for fracture $\left(R R=1.23 ; 95 \% \mathrm{Cl}, 1.12-1.34 ; l^{2}=79.3\right)$, but not significant for PPls combined with $\mathrm{H} 2 \mathrm{RAs}$ use $\left(\mathrm{RR}=1.22 ; 95 \% \mathrm{Cl}, 0.94-1.60 ; I^{2}=44.0 \%\right)$, as well as for $\mathrm{H} 2 \mathrm{RAs}$ use alone ( $\left.\mathrm{RR}=1.08 ; 95 \% \mathrm{Cl}, 0.94-1.24 ; I^{2}=84.1 \%\right)$. Grouping of studies by region showed a significantly increased fracture risk with PPIs use in North America $\left(\mathrm{RR}=1.24 ; 95 \% \mathrm{Cl}, 1.16-1.32 ; l^{2}=0.0 \%\right)$ than in Europe $(\mathrm{RR}=1.23 ; 95 \% \mathrm{Cl}$, $\left.1.00-1.52 ; l^{2}=94.6 \%\right)$ and Asia $(R R=1.10 ; 95 \% \mathrm{Cl}, 0.96-1.25)$. However, there was no significant association between the $\mathrm{H} 2 \mathrm{RAs}$ use and the fracture risk in North America $(\mathrm{RR}=$ 1.08; 95\% Cl, 1.00-1.09; $l^{2}=0.0 \%$ ). Moreover, PPls use showed an increased risk of fracture in women $\left(\mathrm{RR}=1.13 ; 95 \% \mathrm{Cl}, 1.07-1.19 ; l^{2}=0.0 \%\right)$, whereas there was no significant association between the PPls use and the risk of fracture in men $(R R=0.93$; $\left.95 \% \mathrm{Cl}, 0.66-1.31 ; l^{2}=0.0 \%\right)$.

Conclusion: PPIs use alone could increase the risk of fracture in children and young adults, but not for PPls combined with H2RAs use or H2RAs use alone. Clinicians should exercise caution when prescribing PPls for patients.

Keywords: proton pump inhibitors, histamine-2 receptor antagonists, fracture, meta-analysis, medication 


\section{INTRODUCTION}

The use of PPIs and H2RAs among children has substantially increased in recent years (Hales et al., 2018). PPIs and H2RAs have shown to be effective drugs in children as well as in adults with acid-related gastrointestinal disorders, such as Helicobacter pylori infection and gastroesophageal reflux disease (GERD) (Herszényi et al., 2020; Perry et al., 2020). These drugs are generally considered safe, but children are more vulnerable to drug toxicity (Ward and Kearns, 2013). Accordingly, it is critical to clarify the safety of PPIs or H2RAs in children.

In adult studies, PPIs use can significantly increase the risk of fracture, particularly fractures of the spine and hip (Eom et al., 2011a; Kwok et al., 2011; Ngamruengphong et al., 2011). Recent studies have suggested that PPIs may also increase the risk of fracture in children and young adults; there are several biological mechanisms that explain a possible relationship between the PPIs use and the risk of fracture. Some studies found that PPIs can reduce calcium absorption through the inhibition of gastric acid secretion, which leads to increase of the risk of bone fracture (Yang et al., 2006; O'Connell et al., 2005). PPIs may decrease the absorption of vitamin B12 (Lewis et al., 2014), which is associated with bone mineral content and density in elderly women (Dhonukshe-Rutten et al., 2003). Moreover, PPIs might have direct deleterious effects on osteoclast and osteoblast cells, which might result in a reduction in bone turnover (Costa-Rodrigues et al., 2013).

H2RAs are an alternative medication to treat GERD in children and young adults (Cohen et al., 2015). One study showed that H2RAs are safer for the treatment of GERD in children and adolescents (Ruigómez et al., 2017), and there was no significant risk of fracture with H2RAs use (Kwok et al., 2011). However, another study reported a high risk of fracture among young adults receiving H2RAs (Freedberg et al., 2015a). Whether the use of H2RAs or PPIs can significantly increase the risk of fracture is still much debated. A number of studies have investigated the association between the PPIs or H2RAs use and the risk of fracture in children and young adults, but showed inconsistent results. To our knowledge, there is no comprehensive meta-analysis of the related studies yet. Therefore, we conducted such meta-analysis to identify the association between PPIs and/or H2RAs use and the risk of fracture in children and young adults.

\section{METHODS}

The MOOSE guidelines were adhered for meta-analysis of observational studies and PRISMA guidelines (Stroup et al., 2000).

\section{Literature Search Strategy}

PubMed, EMBASE database, Cochrane Library, and Web of Science for relevant articles published before May 2021 were searched by two independent reviewers (Li and Xie). We used the following search terms: "proton pump inhibitors" OR "histamine type 2-receptor antagonists" AND "fracture, bone" OR "broken bones" AND "children" OR “young” OR “young adult” OR "infant” OR “adolescent."

\section{Selection Criteria}

Eligible studies were included if they fulfilled the following criteria: (1) cohort or case control studies, (2) reported on the risk of fracture with PPIs or H2RAs use, (3) the reference group were non-PPIs or -H2RAs users, and (4) studies provided adequate data for the risk estimates. The criteria for exclusion were as follows: (1) studies that only reported on bone density changes, (2) duplicated articles, (3) case reports, reviews, metaanalyses, editorials, and letters, (4) insufficient data, and (5) studies conducted in animals or cell lines.

\section{Data Extraction and Quality Assessment}

The following data were extracted from each study: name of the first author, publication year, study design, country, sample size, age, sex proportion, study period, total participant, duration of follow-up, and effect sizes (risk ratios (RRs), odds ratios (ORs), and hazard ratios (HRs)). The quality of included studies was evaluated using the Newcastle-Ottawa Scale (NOS) (Stang, 2010), wherein a maximum score of nine reflects high quality and an NOS score of seven and eight indicate medium quality (Asbridge et al., 2012). Two authors (Li and Xie) independently extracted the data and assessed the quality of the included studies.

\section{Statistical Analysis}

Analyses were performed using the Stata 12.0 software package. Because the incidence of fracture is sufficiently rare ( $<5 \%$ per year), ORs were considered as approximates of RRs. We extracted HRs, ORs, and RRs from the included studies; otherwise, we calculated unadjusted risk ratio using the raw data. The pooled risk ratio (RR) with 95\% confidence intervals (CIs) from HRs and ORs was calculated using a random-effects model. The $I^{2}$ statistic and Q statistic were used to assess the heterogeneity across the included studies. $I^{2}>50 \%$ and $p<0.05$ indicated significant heterogeneity across studies. We performed a sensitivity analysis by removing one study per time to test the robustness of the results. The publication bias of the included studies was examined by the Begg funnel plot and Egger test.

\section{RESULTS}

We initially identified 114 potentially eligible studies after the literature search process, and after removing 31 duplicated ones, 83 studies remained, in which we excluded 57 other studies which were obviously irrelevant based on the titles and abstracts. Also, after full-text assessment, we eventually identified six studies that could be used for our meta-analysis. The literature search process is illustrated in Figure 1.

\section{Study Characteristics}

Six studies (Freedberg et al., 2015a; Fedida et al., 2019; Malchodi et al., 2019; Wagner et al., 2019; Fleishman et al., 2020; Wang 


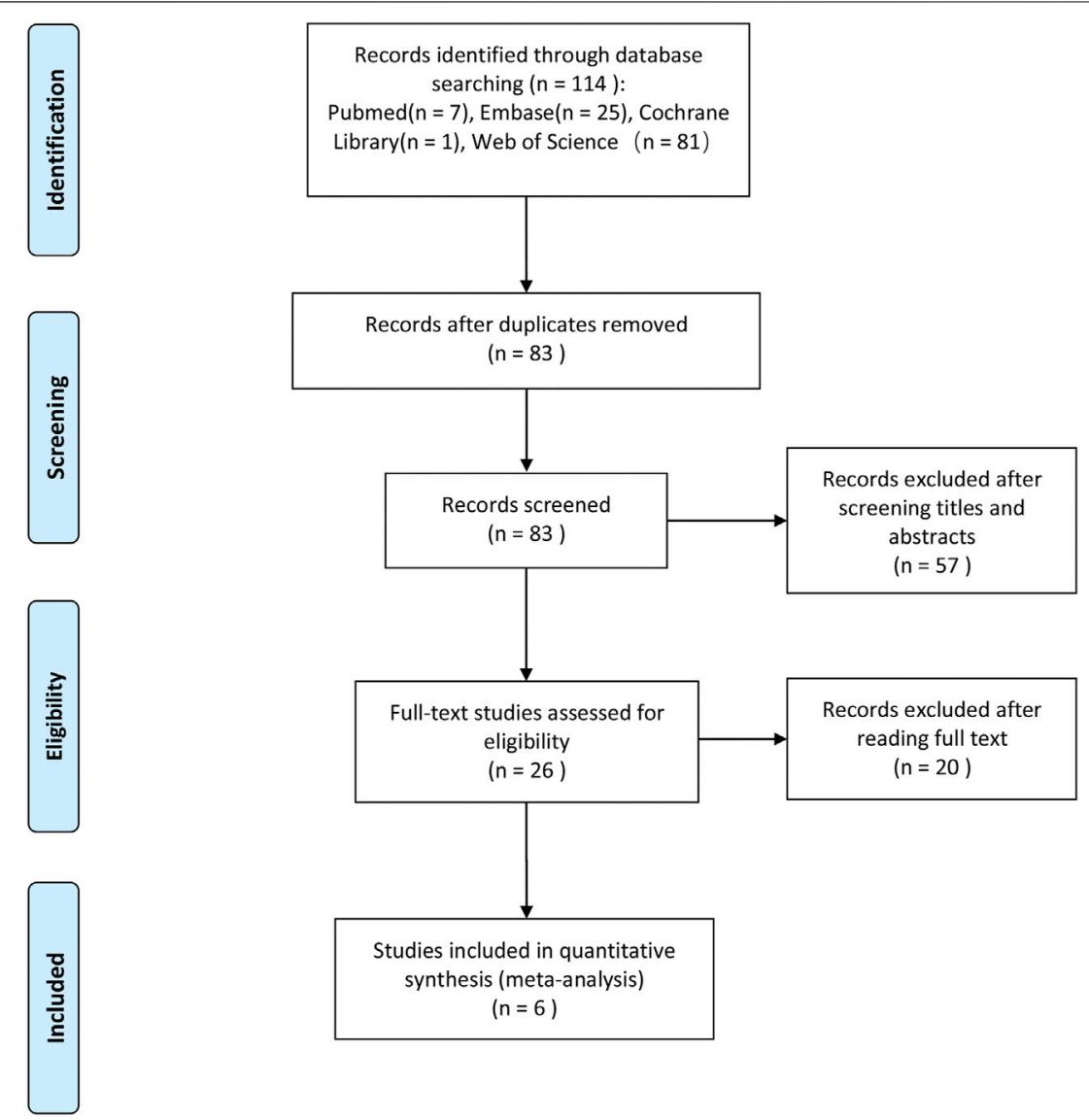

FIGURE 1 | Flow diagram of the literature search process and study inclusion.

TABLE 1 | Characteristics of the six included studies.

\begin{tabular}{|c|c|c|c|c|c|c|c|c|c|}
\hline Study & $\begin{array}{l}\text { Study } \\
\text { design }\end{array}$ & Country & $\begin{array}{c}\text { Age } \\
\text { (years) }\end{array}$ & $\begin{array}{l}\text { Sample } \\
\text { size }\end{array}$ & $\%$ women & $\begin{array}{l}\text { Study } \\
\text { period }\end{array}$ & $\begin{array}{c}\text { Agent: } \\
\text { exposed/unexposed }\end{array}$ & $\begin{array}{l}\text { Follow-up } \\
\text { (years) }\end{array}$ & $\begin{array}{l}\text { NOS } \\
\text { quality } \\
\text { score }\end{array}$ \\
\hline $\begin{array}{l}\text { Fedida } \\
\text { (2019) }\end{array}$ & $\begin{array}{l}\text { Retrospective } \\
\text { cohort }\end{array}$ & Israel & $18-25$ & 488935 & 52 & $2007-2017$ & $\begin{array}{l}\text { PPIs: 998/486372; H2RAs: } \\
\text { 1347/486372; PPIs and H2RAs: } \\
\text { 218/486372 }\end{array}$ & 2 & 6 \\
\hline $\begin{array}{l}\text { Malchodi } \\
\text { (2019) }\end{array}$ & $\begin{array}{l}\text { Retrospective } \\
\text { cohort }\end{array}$ & United States & $3.6-9.1$ & 851631 & 49 & 2001-2003 & $\begin{array}{l}\text { PPIs: 7998/754345; H2RAs: } \\
\text { 71578/754345; PPIs and H2RAs: } \\
\text { 17710/754345 }\end{array}$ & 2 & 9 \\
\hline $\begin{array}{l}\text { Freedberg } \\
\text { (2015) }\end{array}$ & Case control & United Kingdom & $4-29$ & 730442 & 35 & 1994-2013 & $\begin{array}{l}\text { PPIs: 2905/725854; H2RAs: } \\
\text { 1591/725854; PPls and H2RAs: } \\
\text { 92/725854 }\end{array}$ & $\geq 1$ & 6 \\
\hline $\begin{array}{l}\text { Wagner } \\
\text { (2019) }\end{array}$ & $\begin{array}{l}\text { Retrospective } \\
\text { cohort }\end{array}$ & United States & $\geq 5$ & 65432 & 49 & 2009-2010 & PPIs; H2RAs ${ }^{a}$ & $\geq 5$ & 8 \\
\hline $\begin{array}{l}\text { Fleishman } \\
\text { (2020) }\end{array}$ & Cohort & United States & $0.5-15.5$ & 64002 & 48 & 2011-2015 & PPIs: 32001/32001 & 2 & 8 \\
\hline
\end{tabular}

PPIs: proton pump inhibitors; H2RAs: histamine type 2 receptor antagonists.

${ }^{a}$ The original text does not provide exposed and unexposed data, only provide the OR value.

et al., 2020) were included in our meta-analysis following the abovementioned exclusion and selection procedure. The main characteristics of the included studies are summarized in Table 1. They were published between 2015 and 2020 including five cohort studies (Fedida et al., 2019; Malchodi et al., 2019; Wagner et al., 2019; Fleishman et al., 2020; Wang et al., 2020) and one case-control study (Freedberg et al., 2015a). Three studies were conducted in North America (Malchodi et al., 


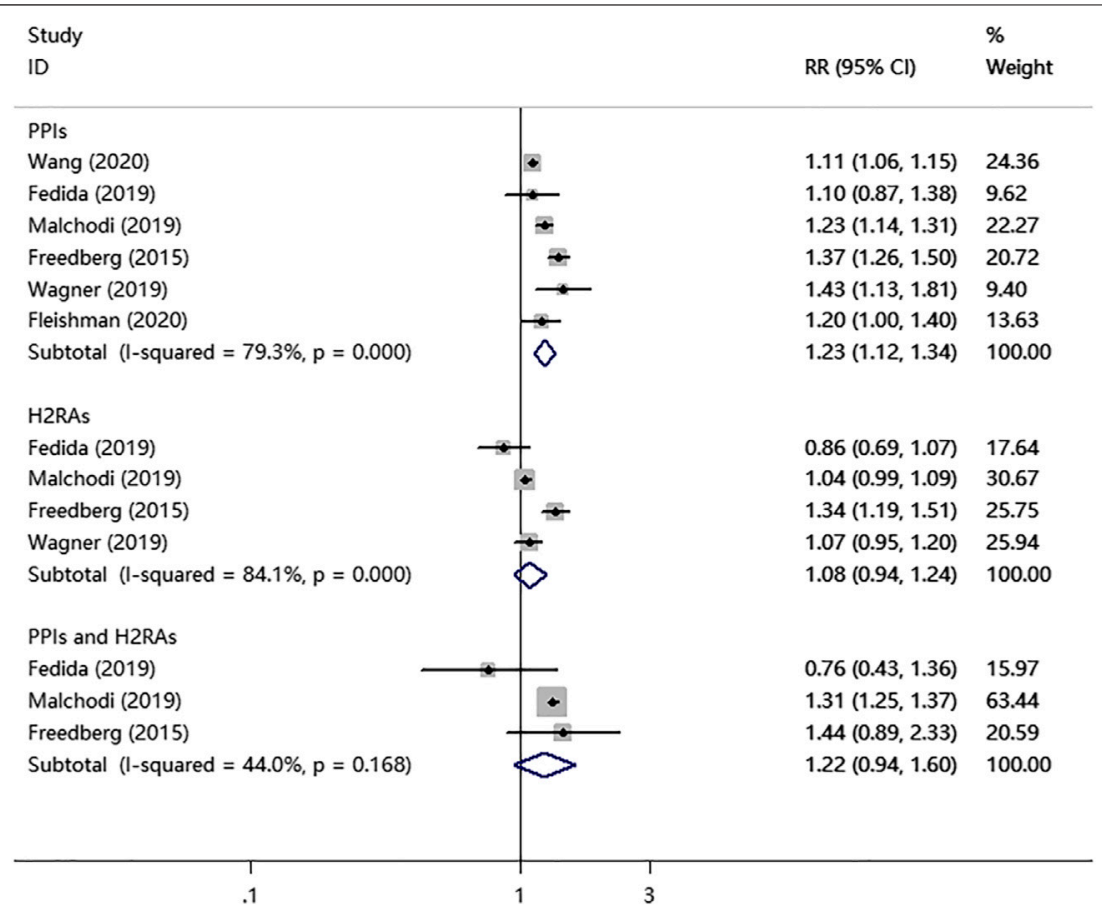

FIGURE 2 | PPIs, H2RAs, or PPIs combined with H2RAs use and the combined risk of fracture in a random-effects model meta-analysis.

TABLE 2 | PPIs, H2RAs, or PPIs combined with H2RAs use and the risk of fracture in subgroup meta-analyses using a random-effects model.

\begin{tabular}{|c|c|c|c|c|c|c|c|c|c|}
\hline \multirow[t]{2}{*}{ Factor } & \multirow[t]{2}{*}{ No. of studies } & \multirow[t]{2}{*}{ RR $(95 \%$ Cl) } & \multicolumn{2}{|c|}{$\begin{array}{c}\text { Heterogeneity } \\
\text { test }\end{array}$} & \multirow[t]{2}{*}{ Factor } & \multirow[t]{2}{*}{ No. of studies } & \multirow[t]{2}{*}{ RR (95\% Cl) } & \multicolumn{2}{|c|}{$\begin{array}{c}\text { Heterogeneity } \\
\text { test }\end{array}$} \\
\hline & & & $I^{2}, \%$ & $p$ Value & & & & $I^{2}, \%$ & $p$ Value \\
\hline Study design & & & & & NOS score & & & & \\
\hline PPls & 6 & $1.23(1.12-1.34)$ & $79.3 \%$ & 0.000 & PPIs & 6 & $1.23(1.12-1.34)$ & $79.3 \%$ & 0.000 \\
\hline Cohort & 5 & $1.18(1.01-1.28)$ & $60.5 \%$ & 0.038 & High $\geq$ (7 point) & 4 & $1.20(1.10-1.31)$ & $70.0 \%$ & 0.018 \\
\hline Case control & 1 & $1.370(1.26-1.50)$ & - & - & Low<(7 point) & 2 & $1.26(1.02-1.55)$ & $67.1 \%$ & 0.081 \\
\hline H2RAs & 4 & $1.08(0.94-1.24)$ & $84.1 \%$ & 0.000 & H2RAs & 4 & $1.08(0.94-1.24)$ & $84.1 \%$ & 0.000 \\
\hline Cohort & 3 & $1.03(0.95-0.11)$ & $35.2 \%$ & 0.214 & High $\geq$ (7 point) & 2 & $1.04(1.00-1.09)$ & $0.0 \%$ & 0.659 \\
\hline Case control & 1 & $1.370(1.26-1.50)$ & - & - & Low<(7 point) & 2 & $1.08(0.70-1.67)$ & $91.8 \%$ & 0.000 \\
\hline PPIs and H2RAs & 3 & $1.22(0.94-1.60)$ & $44.0 \%$ & 0.168 & PPIs and H2RAs & 3 & $1.22(0.94-1.60)$ & $44.0 \%$ & 0.168 \\
\hline Cohort & 2 & $1.08(0.65-1.80)$ & $70.7 \%$ & 0.065 & High $\geq$ (7 point) & 1 & $1.31(1.25-1.37)$ & - & - \\
\hline Case control & 1 & $1.44(0.89-2.33)$ & - & - & Low<(7 point) & 2 & 1.07 (0.57-1.99) & $64.1 \%$ & 0.095 \\
\hline Region & & & & & Outcome & & & & \\
\hline PPIs & 6 & $1.23(1.12-1.3)$ & $79.3 \%$ & 0.000 & PPIs & - & - & - & - \\
\hline North America & 3 & $1.24(1.16-1.32)$ & $0.0 \%$ & 0.448 & Spine & 2 & 1.77 (0.86-3.63) & $69.7 \%$ & 0.069 \\
\hline Europe & 2 & $1.23(1.00-1.52)$ & $94.6 \%$ & 0.000 & Upper limb & 2 & $1.08(1.04-1.13)$ & $0.0 \%$ & 0.590 \\
\hline Asia & 1 & $1.10(0.96-1.25)$ & - & - & Low limb & 2 & $1.24(1.08,1.43)$ & $42.2 \%$ & 0.188 \\
\hline H2RAs & 4 & $1.08(0.94-1.24)$ & $84.1 \%$ & 0.000 & Other fracture & 2 & $1.6(1.26-2.02)$ & $0.0 \%$ & 0.352 \\
\hline North America & 2 & $1.04(1.00-1.09)$ & $0.0 \%$ & 0.659 & Sample size & - & - & - & - \\
\hline Europe & 1 & $1.34(1.19-1.51)$ & - & - & PPIs & - & - & - & - \\
\hline Asia & 1 & $0.86(0.69-1.07)$ & - & - & $>100000$ & 4 & $1.20(1.08-1.33)$ & $86.4 \%$ & 0.000 \\
\hline PPIs and H2RAs & 3 & 1.22 (0.94-1.60) & $44.0 \%$ & 0.168 & $<100000$ & 2 & $1.28(1.09-1.52)$ & $29.1 \%$ & 0.235 \\
\hline North America & 1 & $1.31(1.25-1.37)$ & - & - & Sex (PPIs) & - & - & - & - \\
\hline Europe & 1 & 1.44 (0.89-2.33) & - & - & Men & 2 & $0.93(0.66-1.31)$ & $83.8 \%$ & 0.013 \\
\hline Asia & 1 & $0.76(0.43-1.36)$ & - & - & Women & 2 & $1.13(1.07-1.19)$ & $0.0 \%$ & 0.825 \\
\hline
\end{tabular}

PPIs: proton pump inhibitors; H2RAs: histamine type 2 receptor antagonists; -: heterogeneity cannot be calculated from a single article.

2019; Wagner et al., 2019; Fleishman et al., 2020), two in Europe (Freedberg et al., 2015a; Wang et al., 2020), and one in Israel (Fedida et al., 2019). Six studies evaluated PPIs only; four evaluated H2RAs only; and three studies evaluated both PPIs and H2RAs. As shown in Table 1, the scores measured through the NOS ranged from six to nine points, suggesting that all the 
selected observational studies showed a reasonably good quality.

\section{Main Analysis}

As shown in Figure 2, the PPIs use significantly increased the risk of fracture in children and young adults $(\mathrm{RR}=1.23$; $95 \% \mathrm{CI}$, $\left.1.12-1.34 ; I^{2}=79.3 \%\right)$. In contrast, the H2RAs use did not show a significant association with the fracture risk $(R R=1.08 ; 95 \% \mathrm{CI}$, $\left.0.94-1.24 ; I^{2}=84.1 \%\right)$. Interestingly, PPIs combined with H2RAs use also didn't increase the risk of fracture $(\mathrm{RR}=1.22 ; 95 \% \mathrm{CI}$, $\left.0.94-1.60 ; I^{2}=44.0 \%\right)$.

\section{Subgroup Meta-Analyses}

Table 2 shows the risk of fracture in the subgroup meta-analyses. When the selected studies were grouped by type, we found a significant association between the PPIs use and the risk of fracture in all types. However, a positive association between the use of H2RAs alone and fracture risk was seen only in one case-control study $(\mathrm{RR}=1.37 ; 95 \% \mathrm{CI}, 1.26-1.50)$, and no significant association was seen in the three cohort studies (RR $=1.03 ; 95 \%$ CI, $0.95-0.11 ; I^{2}=35.2 \%$ ).

When we grouped studies by region, we observed that the risk of fracture in patients with the PPIs use was higher in North America $\left(\mathrm{RR}=1.24 ; 95 \% \mathrm{CI}, 1.16-1.32 ; I^{2}=0.0 \%\right)$ and Europe $(\mathrm{RR}=1.23$; $\left.95 \% \mathrm{CI}, 1.00-1.52 ; I^{2}=94.6 \%\right)$ than that in Asia (RR $=1.10 ; 95 \% \mathrm{CI}$, 0.96-1.25). There was no significant association between the H2RAs use and the fracture risk in North America $(\mathrm{RR}=1.08$; 95\% CI, $1.00-1.09 ; I^{2}=0.0 \%$ ); however, the H2RAs use significantly increased the risk of fracture in Europe $(\mathrm{RR}=1.34 ; 95 \% \mathrm{CI}$, 1.19-1.51). There was also a significant positive association between the combined PPIs and H2RAs use and the fracture risk in North America ( $R R=1.31 ; 95 \%$ CI, 1.25-1.37).

Grouping of studies by NOS score showed a significant positive association between the PPIs use and the fracture risk in both the high-quality studies $(\mathrm{RR}=1.20 ; 95 \% \mathrm{CI}$, $\left.1.10-1.31 ; I^{2}=70.0 \%\right)$ and low-quality ones $(\mathrm{RR}=1.26 ; 95 \%$ CI, $\left.1.02-1.55 ; I^{2}=67.1 \%\right)$. In contrast, we found no association between the H2RAs use and the fracture risk in both the highquality studies $\left(\mathrm{RR}=1.04 ; 95 \% \mathrm{CI}, 1.00-1.09 ; I^{2}=0.0 \%\right)$ and low-quality ones $\left(\mathrm{RR}=1.08 ; 95 \% \mathrm{CI}, 0.70-1.67 ; I^{2}=91.8 \%\right)$. Moreover, H2RAs combined with PPIs use has a significant association with the fracture risk in the high-quality studies (RR $=1.31 ; 95 \% \mathrm{CI}, 1.25-1.37)$, but not in the low-quality ones $(\mathrm{RR}=$ 1.07; 95\% CI, 0.57-1.99; $\left.I^{2}=64.1 \%\right)$.

When we grouped studies by sample size, we found a significant association between the PPIs use and the fracture risk in both the studies with more than 100,000 participants included ( $\left.\mathrm{RR}=1.20 ; 95 \% \mathrm{CI}, 1.08-1.33 ; I^{2}=86.4 \%\right)$ and those with less than 100,000 participants included $(R R=1.28 ; 95 \% \mathrm{CI}$, $\left.1.09-1.52 ; I^{2}=29.1 \%\right)$.

In the subgroup meta-analyses by fracture outcome, the PPIs use increased the risk of low limb fracture $(\mathrm{RR}=1.24 ; 95 \% \mathrm{CI}$, $\left.1.08-1.43 ; I^{2}=42.2 \%\right)$, and other fracture (RR $=1.6 ; 95 \% \mathrm{CI}$, $\left.1.26-2.02 ; I^{2}=0.0 \%\right)$.

The subgroup analyses by sex showed a significant association between the PPIs use and the risk of fracture in women $(\mathrm{RR}=$ $\left.1.13 ; 95 \% \mathrm{CI}, 1.07-1.19 ; I^{2}=0.0 \%\right)$, whereas there was no significant association between the PPIs use and the risk of fracture in men $\left(\mathrm{RR}=0.93 ; 95 \% \mathrm{CI}, 0.66-1.31 ; I^{2}=0.0 \%\right)$.

\section{Sensitivity Analysis and Publication Bias}

The results of the sensitivity analysis demonstrated the stability of outcomes in meta-analyses. Begg's test and Egger's test were conducted, and there was no evidence for publication bias detected in all the analyses.

\section{DISCUSSION}

In this meta-analysis concerning the six selected observational studies, we found an increased risk of fracture with the PPIs use alone or the PPIs combined with H2RAs use in children and young adults, but not with the H2RAs use alone, which is consistent with the meta-analysis results of the acid-suppressing medication and fracture risk in adults (Kwok et al., 2011; Freedberg et al., 2015a). Besides, the use of PPIs or H2RAs increased the risk of fracture more significantly in one case-control study as compared to the cohort studies. However, it is generally considered that cohort studies provide superior evidence compared with case-control studies because cohort studies are less susceptible to bias in the prospective design. As a result, the results obtained from this metaanalysis should be interpreted with caution. Interestingly, the subgroup analyses by sex showed that the PPIs use increased the risk of fracture in women, but not in men. The subgroup analyses by fracture outcome showed an increased risk of spine, low limb, and other fracture for the PPIs use. The region of the study conducted may be one of the sources of heterogeneity among the studies. After limiting to North America, there was low heterogeneity across the related studies $\left(I^{2}=0.0 \%, p>0.05\right)$.

PPIs use is becoming increasingly common, and there has been an observed increase in the risk of gastrointestinal and respiratory tract infection (Eom et al., 2011b; Freedberg et al., 2015b), hypomagnesaemia, vitamin B12 deficiency, and bone fracture (De Bruyne and Ito, 2018). Particularly, the use of PPIs or H2RAs might increase the risk of bone fracture and osteoporosis (Targownik et al., 2010; Liu et al., 2019). The risk of fracture with PPIs use was higher than that with H2RAs use, which might be explained by a few reasons. First, PPIs have a stronger inhibitory effect on the acid production than H2RAs; the latter only suppress $70 \%$ of gastric acid production (Colin-Jones, 1995), whereas the former, PPIs, block 98\% of the acid production (Schuler, 2007). Insoluble calcium salt from diet is difficult to absorb (Insogna, 2009), and the ionized calcium from insoluble calcium salts is promoted to release in the acidic environment of the stomach; thus, the reduced acid production could impair calcium absorption (O'Connell et al., 2005). Second, it was also reported that calcium malabsorption would cause hyperparathyroidism, thus leading to the reduction of bone mineral density (Insogna, 2009). Third, PPIs use could reduce vitamin B12 absorption, which may increase the risk of fracture as well (Marcuard et al., 1994). Fourth, cimetidine, one of the H2RAs, has been shown to increase bone mineral density by preventing osteoclast differentiation induced by histamine (Yamaura et al., 2003). Similarly, Vesterdaard et al. (2006) found that PPIs use might increase the risk of fracture whereas the H2RAs 
use decreases the risk. Although PPIs use was associated with increased risk of fracture, some studies found that there was no significant difference between the PPIs use and the level of bone mineral density (Targownik et al., 2010; Targownik et al., 2012; Hansen et al., 2019). Last, PPIs might increase the incidence of nonosteoporotic fracture by increasing the risk of falling (Thaler et al., 2016).

Our meta-analysis has several strengths. First, there were several previous meta-analyses on the fracture risk with PPIs or H2RAs use in the elderly. However, the current meta-analysis is the first to review the PPIs use and fracture risk in children and young adults. Second, it examined the associations stratified by the type of agent (PPIs or H2RAs), the study design, region, NOS score, outcome, and sample size, as well as sex. However, our meta-analysis also has several limitations. First, there was no available RCT on the issue, so our study consisted entirely of observational studies, which are also susceptible to various biases. Second, the number of eligible studies selected in our meta-analysis was relatively small. Third, some potential studies might have been missed with the language of publications restricted to English only.

\section{CONCLUSION}

In summary, this meta-analysis of observational studies showed that PPIs use alone could increase the risk of fracture in children

\section{REFERENCES}

Asbridge, M., Hayden, J. A., and Cartwright, J. L. (2012). Acute Cannabis Consumption and Motor Vehicle Collision Risk: Systematic Review of Observational Studies and Meta-Analysis. BMJ 344, e536. Epub 2012/02/ 11PubMed PMID: 22323502; PubMed Central PMCID: PMCPMC3277079. doi:10.1136/bmj.e536

Cohen, S., Bueno de Mesquita, M., and Mimouni, F. B. (2015). Adverse Effects Reported in the Use of Gastroesophageal Reflux Disease Treatments in Children: a 10 Years Literature Review. Br. J. Clin. Pharmacol. 80 (2), 200-208. Epub 2015/03/11PubMed PMID: 25752807; PubMed Central PMCID: PMCPMC4541968. doi:10.1111/bcp.12619

Colin-Jones, D. G. (1995). The Role and Limitations of H2-Receptor Antagonist in the Treatment of Gastro-Oesophageal Refrux Disease. Aliment. Pharmacol. Ther. 9 (Suppl. 1), 9-14. Epub 1995/01/01PubMed PMID: 7495945. doi:10.1111/j.1365-2036.1995.tb00778.x

Costa-Rodrigues, J., Reis, S., Teixeira, S., Lopes, S., and Fernandes, M. H. (2013). Dose-dependent Inhibitory Effects of Proton Pump Inhibitors on Human Osteoclastic and Osteoblastic Cell Activity. FEBS J. 280 (20), 5052-5064. Epub 2013/08/14PubMed PMID: 23937530. doi:10.1111/febs.12478

De Bruyne, P., and Ito, S. (2018). Toxicity of Long-Term Use of Proton Pump Inhibitors in Children. Arch. Dis. Child. 103 (1), 78-82. Epub 2017/12/ 15PubMed PMID: 29237614. doi:10.1136/archdischild-2017-314026

Dhonukshe-Rutten, R. A. M., Lips, M., de Jong, N., Chin A Paw, M. J. M., Hiddink, G. J., van Dusseldorp, M., et al. (2003). Vitamin B-12 Status Is Associated with Bone mineral Content and Bone mineral Density in Frail Elderly Women but Not in Men. J. Nutr. 133 (3), 801-807. Epub 2003/03/04PubMed PMID: 12612156. doi:10.1093/jn/133.3.801

Eom, C.-S., Jeon, C. Y., Lim, J.-W., Cho, E.-G., Park, S. M., and Lee, K.-S. (2011). Use of Acid-Suppressive Drugs and Risk of Pneumonia: a Systematic Review and Meta-Analysis. Can. Med. Assoc. J. 183 (3), 310-319. Epub 2010/12/ 22PubMed PMID: 21173070; PubMed Central PMCID: PMCPMC3042441. doi:10.1503/cmaj.092129 and young adults, but not for PPIs combined with H2RAs use or H2RAs use alone. Clinicians should carefully assess the risk of fracture before prescribing PPIs for patients. Further studies are required to confirm our findings reported hereby due to the inevitable limitations of this meta-analysis.

\section{DATA AVAILABILITY STATEMENT}

The raw data supporting the conclusions of this article will be made available by the authors, without undue reservation.

\section{AUTHOR CONTRIBUTIONS}

JL and XX designed the study and collected data. JL drafted the manuscript. WL, FG, KZ, ZS, QW, ZS, and PZ contributed to the writing. TY provided critical feedback and contributed to the review of the manuscript. All authors contributed to the article and approved the submitted version.

\section{FUNDING}

This study was supported by the National Natural Science Foundation of China (Grant No. 31970090).

Eom, C.-S., Park, S. M., Myung, S.-K., Yun, J. M., and Ahn, J.-S. (2011). Use of Acid-Suppressive Drugs and Risk of Fracture: a Meta-Analysis of Observational Studies. Ann. Fam. Med. 9 (3), 257-267. Epub 2011/05/11PubMed PMID: 21555754; PubMed Central PMCID: PMCPMC3090435. doi:10.1370/afm.1243

Fedida, B., Schermann, H., Ankory, R., Rotman, D., Shichman, I., Yoffe, V., et al. (2019). Fracture Risk of Young Adults Receiving Proton-pump Inhibitors and H2-receptor Antagonists. Int. J. Clin. Pract. 73 (5), e13339. Epub 2019/03/ 05PubMed PMID: 30829427. doi:10.1111/ijcp.13339

Fleishman, N., Richardson, T., and Attard, T. (2020). The Clinical Characteristics of Fractures in Pediatric Patients Exposed to Proton Pump Inhibitors. J. Pediatr. Gastroenterol. Nutr. 70 (6), 815-819. Epub 2020/05/23PubMed PMID: 32443038. doi:10.1097/MPG.0000000000002690

Freedberg, D. E., Haynes, K., Denburg, M. R., Zemel, B. S., Leonard, M. B., Abrams, J. A., et al. (2015). Use of Proton Pump Inhibitors Is Associated with Fractures in Young Adults: a Population-Based Study. Osteoporos. Int. 26 (10), 2501-2507. Epub 2015/05/20PubMed PMID: 25986385; PubMed Central PMCID: PMCPMC4575851. doi:10.1007/s00198-015-3168-0

Freedberg, D. E., Lamousé-Smith, E. S., Lightdale, J. R., Jin, Z., Yang, Y.-X., and Abrams, J. A. (2015). Use of Acid Suppression Medication Is Associated with Risk forC. difficileInfection in Infants and Children: A Population-Based Study. Clin. Infect. Dis. 61 (6), 912-917. Epub 2015/06/11PubMed PMID: 26060292; PubMed Central PMCID: PMCPMC4551005. doi:10.1093/cid/civ432

Hales, C. M., Kit, B. K., Gu, Q., and Ogden, C. L. (2018). Trends in Prescription Medication Use Among Children and Adolescents-United States, 1999-2014. JAMA 319 (19), 2009-2020. Epub 2018/05/26PubMed PMID: 29800213; PubMed Central PMCID: PMCPMC6583241. doi:10.1001/jama.2018.5690

Hansen, K. E., Nieves, J. W., Nudurupati, S., Metz, D. C., and Perez, M. C. (2019). Dexlansoprazole and Esomeprazole Do Not Affect Bone Homeostasis in Healthy Postmenopausal Women. Gastroenterology 156 (4), 926-934. Epub 2018/11/18PubMed PMID: 30445008. doi:10.1053/j.gastro.2018.11.023

Herszényi, L., Bakucz, T., Barabás, L., and Tulassay, Z. (2020). Pharmacological Approach to Gastric Acid Suppression: Past, Present, and Future. Dig. Dis. 38 (2), 104-111. Epub 2019/12/18PubMed PMID: 31846972. doi:10.1159/ 000505204 
Insogna, K. L. (2009). The Effect of Proton Pump-Inhibiting Drugs on mineral Metabolism. Am. J. Gastroenterol. 104 (Suppl. 2), S2-S4. Epub 2009/03/06 PubMed PMID: 19262542. doi:10.1038/ajg.2009.44

Kwok, C. S., Yeong, J. K.-Y., and Loke, Y. K. (2011). Meta-analysis: Risk of Fractures with Acid-Suppressing Medication. Bone 48 (4), 768-776. Epub 2010/ 12/28PubMed PMID: 21185417. doi:10.1016/j.bone.2010.12.015

Lewis, J. R., Barre, D., Zhu, K., Ivey, K. L., Lim, E. M., Hughes, J., et al. (2014). Longterm Proton Pump Inhibitor Therapy and Falls and Fractures in Elderly Women: a Prospective Cohort Study. J. Bone Miner Res. 29 (11), 2489-2497. Epub 2014/05/16PubMed PMID: 24825180. doi:10.1002/jbmr.2279

Liu, J., Li, X., Fan, L., Yang, J., Wang, J., Sun, J., et al. (2019). Proton Pump Inhibitors Therapy and Risk of Bone Diseases: An Update Meta-Analysis. Life Sci. 218, 213-223. Epub 2019/01/04PubMed PMID: 30605646. doi:10.1016/ j.lfs.2018.12.058

Malchodi, L., Wagner, K., Susi, A., Gorman, G., and Hisle-Gorman, E. (2019). Early Acid Suppression Therapy Exposure and Fracture in Young Children. Pediatrics 144 (1), e20182625 Epub 2019/06/09PubMed PMID: 31175146. doi:10.1542/peds.2018-2625

Marcuard, S. P., Albernaz, L., and Khazanie, P. G. (1994). Omeprazole Therapy Causes Malabsorption of Cyanocobalamin (Vitamin B_12). Ann. Intern. Med. 120 (3), 211-215. Epub 1994/02/01PubMed PMID: 8273984. doi:10.7326/00034819-120-3-199402010-00006

Ngamruengphong, S., Leontiadis, G. I., Radhi, S., Dentino, A., and Nugent, K. (2011). Proton Pump Inhibitors and Risk of Fracture: a Systematic Review and MetaAnalysis of Observational Studies. Am. J. Gastroenterol. 106 (7), 1209-1218. quiz 19. Epub 2011/04/13PubMed PMID: 21483462. doi:10.1038/ajg.2011.113

O’Connell, M. B., Madden, D. M., Murray, A. M., Heaney, R. P., and Kerzner, L. J. (2005). Effects of Proton Pump Inhibitors on Calcium Carbonate Absorption in Women: a Randomized Crossover Trial. Am. J. Med. 118 (7), 778-781. Epub 2005/07/02PubMed PMID: 15989913. doi:10.1016/j.amjmed.2005.02.007

Perry, I. E., Sonu, I., Scarpignato, C., Akiyama, J., Hongo, M., and Vega, K. J. (2020). Potential Proton Pump Inhibitor-Related Adverse Effects. Ann. N.Y. Acad. Sci. 1481 (1), 43-58. Epub 2020/08/08PubMed PMID: 32761834. doi:10.1111/nyas.14428

Ruigómez, A., Johansson, S., Nagy, P., and García Rodríguez, L. A. (2017). Utilization and Safety of Proton-Pump Inhibitors and Histamine-2 Receptor Antagonists in Children and Adolescents: an Observational Cohort Study. Curr. Med. Res. Opin. 33 (12), 2201-2209. Epub 2017/07/13PubMed PMID: 28699796. doi:10.1080/03007995.2017.1354830

Schuler, A. (2007). Risks versus Benefits of Long-Term Proton Pump Inhibitor Therapy in the Elderly. Geriatr. Nurs. 28 (4), 225-229. Epub 2007/10/ 17PubMed PMID: 17936957. doi:10.1016/j.gerinurse.2007.06.009

Stang, A. (2010). Critical Evaluation of the Newcastle-Ottawa Scale for the Assessment of the Quality of Nonrandomized Studies in Meta-Analyses. Eur. J. Epidemiol. 25 (9), 603-605. Epub 2010/07/24PubMed PMID: 20652370. doi:10.1007/s10654-010-9491-z

Stroup, D. F., Berlin, J. A., Morton, S. C., Olkin, I., Williamson, G. D., Rennie, D., et al. (2000). Meta-analysis of Observational Studies in EpidemiologyA Proposal for Reporting. JAMA 283 (15), 2008-2012. Epub 2000/05/ 02PubMed PMID: 10789670. doi:10.1001/jama.283.15.2008

Targownik, L. E., Leslie, W. D., Davison, S. K., Goltzman, D., Jamal, S. A., Kreiger, N., et al. (2012). The Relationship between Proton Pump Inhibitor Use and Longitudinal Change in Bone Mineral Density: A Population-Based from the Canadian Multicentre Osteoporosis Study (CaMos). Am. J. Gastroenterol. 107
(9), 1361-1369. Epub 2012/07/11PubMed PMID: 22777336; PubMed Central PMCID: PMCPMC5104563. doi:10.1038/ajg.2012.200

Targownik, L. E., Lix, L. M., Leung, S., and Leslie, W. D. (2010). Proton-pump Inhibitor Use Is Not Associated with Osteoporosis or Accelerated Bone mineral Density Loss. Gastroenterology 138 (3), 896-904. Epub 2009/11/26PubMed PMID: 19931262. doi:10.1053/j.gastro.2009.11.014

Thaler, H. W., Sterke, C. S., and van der Cammen, T. J. M. (2016). Association of Proton Pump Inhibitor Use with Recurrent Falls and Risk of Fractures in Older Women: A Study of Medication Use in Older Fallers. J. Nutr. Health Aging 20 (1), 77-81. Epub 2016/01/06PubMed PMID: 26728937. doi:10.1007/s12603016-0679-0

Vestergaard, P., Rejnmark, L., and Mosekilde, L. (2006). Proton Pump Inhibitors, Histamine H2 Receptor Antagonists, and Other Antacid Medications and the Risk of Fracture. Calcif Tissue Int. 79 (2), 76-83. Epub 2006/08/24PubMed PMID: 16927047. doi:10.1007/s00223-006-0021-7

Wagner, K., Wagner, S., Susi, A., Gorman, G., and Hisle-Gorman, E. (2019). Prematurity Does Not Increase Early Childhood Fracture Risk. J. Pediatr. 207, 148-153. Epub 2018/12/12PubMed PMID: 30528571. doi:10.1016/ j.jpeds.2018.11.017

Wang, Y.-H., Wintzell, V., Ludvigsson, J. F., Svanström, H., and Pasternak, B. (2020). Association between Proton Pump Inhibitor Use and Risk of Fracture in Children. JAMA Pediatr. 174 (6), 543-551. Epub 2020/03/17PubMed PMID: 32176276; PubMed Central PMCID: PMCPMC7076540. doi:10.1001/ jamapediatrics.2020.0007

Ward, R. M., and Kearns, G. L. (2013). Proton Pump Inhibitors in Pediatrics. Pediatr. Drugs 15 (2), 119-131. Epub 2013/03/21PubMed PMID: 23512128; PubMed Central PMCID: PMCPMC3616221. doi:10.1007/s40272-013-0012-x

Yamaura, K., Yonekawa, T., Nakamura, T., Yano, S., and Ueno, K. (2003). The Histamine H2-Receptor Antagonist, Cimetidine, Inhibits the Articular Osteopenia in Rats with Adjuvant-Induced Arthritis by Suppressing the Osteoclast Differentiation Induced by Histamine. J. Pharmacol. Sci. 92 (1), 43-49. Epub 2003/07/02 PubMed PMID: 12832854. doi:10.1254/jphs.92.43

Yang, Y.-X., Lewis, J. D., Epstein, S., and Metz, D. C. (2006). Long-term Proton Pump Inhibitor Therapy and Risk of Hip Fracture. JAMA 296 (24), 2947-2953. Epub 2006/12/28PubMed PMID: 17190895. doi:10.1001/jama.296.24.2947

Conflict of Interest: The authors declare that the research was conducted in the absence of any commercial or financial relationships that could be construed as a potential conflict of interest.

Publisher's Note: All claims expressed in this article are solely those of the authors and do not necessarily represent those of their affiliated organizations, or those of the publisher, the editors and the reviewers. Any product that may be evaluated in this article, or claim that may be made by its manufacturer, is not guaranteed or endorsed by the publisher.

Copyright (c) $2021 \mathrm{Li}$, Xie, Liu, Gu, Zhang, Su, Wen, Sui, Zhou and Yu. This is an open-access article distributed under the terms of the Creative Commons Attribution License (CC BY). The use, distribution or reproduction in other forums is permitted, provided the original author(s) and the copyright owner(s) are credited and that the original publication in this journal is cited, in accordance with accepted academic practice. No use, distribution or reproduction is permitted which does not comply with these terms. 